\title{
SUPERBROTAMENTO DE INFLORESCÊNCIAS DO LIMÃO-DE-CAIENA CAUSADO POR Fusarium decemcellulare
}

\author{
CLEBER N. BASTOS ${ }^{1} \&$ AUGUSTO O. SANTOS
}

Comissão Executiva do Plano da Lavoura Cacaueira/Superintendência da Amazônia Oriental, Cx. Postal 5150, CEP 66.035-110, Belém-PA, e-mail: cleber@ufpa.br

(Aceito para publicação em 13/02/2001)

Autor para correspondência: Cleber N. Bastos

\section{ABSTRACT \\ Oversprouting of inflorescences of the limão-de-Caiena caused by Fusarium decemcellulare}

Fusarium decemcellulare is described as causing oversprouting of the inflorescences of limão-de-Caiena
(Averrhoa bilimbi) in the State of Pará, Brazil. Pathogenicity of the fungus was confirmed by artificial inoculations
O limão-de-Caiena (Averrhoa bilimbi L.) também conhecido por bilimbizeiro, da família Averrhoaceae, produz frutos que geralmente são processados salgados ou doces para confecção de conservas em picles, condimentos e molhos. Quando maduros, esses são utilizados em geléias e compotas, constituindo boa fonte de vitamina C (Donadio et al., Frutas Exóticas, 1998). Recentemente foi observado no município de Icoaraci, PA, pés de limão-de-Caiena apresentando anormalidade nas inflorescências. Os sintomas se manifestam tanto no tronco, como nos ramos e caracterizam-se pelo desenvolvimento anormal de superbrotamento das inflorescências a partir do eixo floral, com inchamento dos talos florais. As flores e frutos jovens, geralmente caem prematuramente e os talos ficam totalmente secos (Figura 1). Material infetado foi coletado e levado para o laboratório de Fitopatologia da Ceplac, em Belém, PA, para isolamento do agente causal. Os isolamentos procedidos em BDA, a partir de fragmentos de tecidos retirados de ramos infetados, revelaram a constante presença de um fungo, cujas características morfológicas foi identificado como Fusarium decemcellulare Brick [ = Calonectria rigidiuscula (Berk \& Br.)Sacc)] (Booth, C. The genus Fusarium. Commonwealth Mycological Institute, 1971). Culturas em BDA esporulam abundantemente formando massas de esporos de cor amarelo limão contrastando com a coloração róseo intensa do meio. Os macroconídios medem de 55-130 x 6-10 $\mu \mathrm{m}$, são septados, com 7-10 septos. O teste de patogenicidade foi realizado em inflorescências de bilimbizeiro, feridas com um alfinete esterilizado e sobre a região ferida foi atomizado o inóculo na concentração de $10^{5}$ conídios $/ \mathrm{ml}$. Em seguida, as inflorescências foram envolvidas com sacos plásticos contendo nos

\footnotetext{
${ }^{1}$ Bolsista do $\mathrm{CNPq}$
}

seus interiores um chumaço de algodão embebido em água destilada esterilizada. Sintomas de superbrotamento apareceram 45 dias após a inoculação e o patógeno reisolado dos tecidos infectados, comprovando-se a etiologia da doença. Não foi encontrado relato sobre a ocorrência de $F$. decemcellulare em limão-de-Caiena. Existem registros desse patógeno associado à formação de superbrotamento e galhas em alguns hospedeiros, como cacaueiro (Theobroma cacao L.), mangueira (Mangifera indica L.), cafeeiro (Coffea arabica L.), guaranazeiro (Paullinia cupana Ducke), frejó (Cordia olliodora L.) e cedro (Cedrela odorata L.) (Brunt \& Wharton. Ann. Appl. Biol. 50: 283-289. 1962; Duarte et al., Fitopatol. Bras. 7: 129-131. 1982; Albuquerque \& Bastos, Fitopatol. Bras. 15:252-253. 1990; Lori et al., Fitopatol. Bras. 19:476-478. 1994).

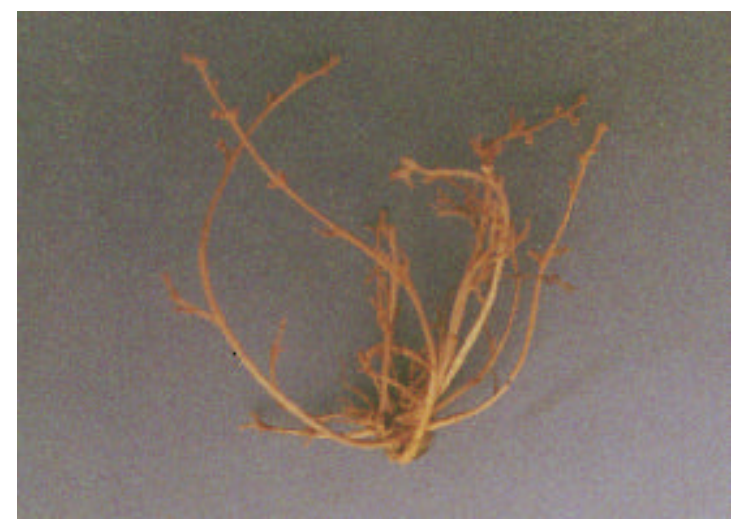

FIG. 1 - Sintomas de superbrotamento de inflorescências de limão-de-Caiena (Averrhoa bilimbi) causados por Fusarium decemcellulare. 